\title{
GW23-e2488 CLINICAL STUDY ON ASSESSEMENT OF LEFT VENTRICULAR FUNCTION IN PATIENTS WITH EARLY TYPE 2 DIABETES MELLITUS WITH WAVE INTENSITY
}

doi:10.1136/heartjnl-2012-302920ad.24

Tian Xinqiao, Zhu Hong, Ru Ao, Wu Chaoming, Zhang Chao, Yang Yan, Zhou Juan, Liu Min, Zheng Lei, Tian Xinqiao. Department of Ultrasonography, The Second Affiliated Hospital of Wenzhou Medical College

Objectives To investigate the clinical value of wave intensity (WI) in assessing left ventricular function of patients with early type 2 diabetes mellitus and combined with hypertension.

Methods Twenty-one patients with type 2 diabetes mellitus (T2DM) and 25 T2DM patients combined with essential hypertension group $(\mathrm{T} 2 \mathrm{DM}+\mathrm{EH})$, all of left ventricular ejection fraction (LVEF) in two groups of patients were ${ }^{3} 50 \%$, were enrolled in this study, and 25 healthy volunteers were taken as control group. Each patient underwent echocardiographic and WI exam. The indexes of conventional echocardiography and WI including W1, W2, R-W1 and W1-W2 of right common carotid artery (CCA) in three groups were measured and compared.

Results No statistically significant difference was found for LVEF in three groups. Prorsad expanded wave peak W2 in T2DM group increased more obviously than that in the control group ( 3.5308 $\pm 1.0980 \mathrm{~mm} \mathrm{Hg} \mathrm{m} / \mathrm{s}^{3}$ vs $\left.2.1240 \pm 0.6870 \mathrm{~mm} \mathrm{Hg} \mathrm{m} / \mathrm{s}^{3}, \quad \mathrm{p}<0.01\right)$. Prorsad compressed wave peak W1 in T2DM group was higher than that in control group $\left(13.3769 \pm 7.2140 \mathrm{~mm} \mathrm{Hg} \mathrm{m} / \mathrm{s}^{3}\right.$ vs $\left.9.0600 \pm 3.3257 \mathrm{~mm} \mathrm{Hg} \mathrm{m} / \mathrm{s}^{3}, \mathrm{p}<0.05\right)$. Time of W1-W2 in T2DM group was significantly shortened compared with control group $(234.8 \pm 29.1 \mathrm{~ms}$ vs $276.1 \pm 22.8 \mathrm{~ms}, \mathrm{p}<0.01)$. Compared with the control group, $\mathrm{Wl}$ in $\mathrm{T} 2 \mathrm{DM}+\mathrm{EH}$ group was more obviously higher $\left(20.0957 \pm 10.5663 \mathrm{~mm} \mathrm{Hg} \mathrm{m} / \mathrm{s}^{3}\right.$ vs $9.0600 \pm 3.3257 \mathrm{~mm} \mathrm{Hg} \mathrm{m} / \mathrm{s}^{3}$, $\mathrm{p}<0.01)$, and $\mathrm{W} 2$ increased significantly $(2.8522$ $\pm 1.6223 \mathrm{~mm} \mathrm{Hg} \mathrm{m} / \mathrm{s}^{3}$ vs $\left.2.1240 \pm 0.6870 \mathrm{~mm} \mathrm{Hg} \mathrm{m} / \mathrm{s}^{3}, \quad \mathrm{p}<0.05\right)$. $\mathrm{Wl}$ in T2DM+EH group was higher than that in T2DM group $(p<0.05)$. W2 in T2DM+EH group reduced than that in T2DM group, but no statistically significant difference was found between the two groups.

Conclusions WI can be used as new method to evaluate left ventricular dysfunction in patients with early type 2 diabetes mellitus and T2DM combined with EH. 